\title{
LITERARY JOURNALISM: COMMUNICATION TACTICS OF DIFFERENT DIALOGUES IN ENGLISH CONTENT
}

\author{
Oleg Kharchenko \\ Candidate of Philological Sciences, Associate Professor at the Department of Publishing, \\ Borys Grinchenko Kyiv University, Ukraine \\ e-mail: ov.kharchenko@kubg,edu.ua, orcid.org/0000-0002-6263-4573
}

\section{Summary}

The article spotlights the issues of the English-speaking literary journalism, as a direction of non-fiction, blending literary styles and narrative techniques, giving the exact information, while composing features, opinion articles, chronicles, travel blogs, listicles, biographies, essays, and other articles. The article tackles the communication strategies and tactics, stylistic and literary devices, applied in literature, and respectively in journalism and nonfiction by English-speaking authors. Among the smorgasbord of literary devices used in American and British literary journalism, it is vital to underline the importance of a dialogue, a strict chronological structure, some status details, and the text presentation from the third-person perspective.

In the article, the dialogue is regarded in the classical meaning as communication and exchange of information or conversation in written or oral form between two or several people, as well as a literary or theatrical form that presents such exchange.

The content analyses of American and British mass media, as well as their monitoring and empirical identification of active types of dialogues, transmitting from American and British literature into the literary journalism, belong to the key methods of research and further analysis.

As a result of the scholarly survey, sixteen types of dialogues, leading to the better plot outlining were determined, the employment of which could diversify and improve the quality of English content made by Ukrainian students, journalists and nonfiction writers. The article characterizes and gives examples of the following types of dialogues, which are apt to the contemporary English speaking literature and non-fiction: Cryptic Conversation; Cultural Contrast; Appeal to family wisdom; Trial balloon dialogue; Blatant Lies; Con artist lies dialogue; Constant cheering; Berate and switch; Casual danger; Bread, Eggs, Milk, Squeak; Derailed Train of Thought; Sliding into Gibberish; Digging Yourself Deeper; Volleying Insults; Insult backfire; Contradiction of Arguments' Dialogue.

The strategies of cooperation, confrontation, manipulation and entertainment are singled out as the main communication strategies for the majority of determined dialogues.

Keywords: English textual content, literary journalism, literary devices, dialogue, communicative tactics, stylistic figures, communicative strategy, etc.

DOI: https://doi.org/10.23856/4507

\section{Introduction}

H. Hornmoen and S. Steensen affirm that interview entered American journalism in the 1830s. Founded on dialogical communication, it advanced the tabloid and penny press in the time of the Pre-objectivity era. During the time of the Objectivity era, from 1914 till the 1960s, it transformed into a method of many journalistic cultures (Hornmoen, Steensen, 2014). 
Literary journalism, initiated in the Period of the New Journalism era, it was in the 1960s, as T. Wolfe and E.W. Johnson assert, was built on four main literary devices: dialogue, scene-by-scene construction, status details and third-person narrative (Wolfe, Johnson, 1975). Since that time different types of literary dialogues began infiltrating in journalistic writing including editorials, opinion articles, listicles, literary reportage, travelling blogs, book reviews, essays, biographies, and other blended forms.

The Digital era of journalism, with the wide incursion of social networks, just erased the edges between colloquial speech, literature and journalism, breaking the flood locks to more and more varied variants of dialogues.

Accepting the classical structure classifications of dialogues on directed (two persons engaged) and misdirected (three or four persons engaged, etc.), modulated (with minor points, retrospections, and observations), and interpolated options (insertions, interpretations, and explanations, etc.) (Thai, 2017), in this article, we dwell our attention on dialogue types having diverse communicative goals and using communicative tactics, which could be determined in the present-day American and British literature and journalism.

At the same time, we identify the dialogue traditionally as a literary or journalistic technique in which two or more persons take part in conversations with each other. It is a conversational discourse about the same theme.

While regarding dialogues within communicative and stylistic frames, we indicate that D. Levy defines the communicative strategy as "any strategy is a cognitive process, in which a sender correlates his or her communicative goal with some definite language expression" (Levy, 1979:19).

In our opinion, a communicative strategy of literary discourse as well as journalistic discourse could be defined as the process of formation and application of some well-outlined communicative goal, which is set because of some efficient influence and getting the feedback of an audience.

Under communicative tactics we recognize the set of language means (typically stylistic tools) which lead to some effect and the ways of realization of some well-defined strategy.

Our scientific survey of American literature and multimedia content permitted us to identify the following types of dialogues.

\section{Dialogue Types}

1. 'Cryptic Conversation' Dialogue. It a kind of a dialogue when an addresser uses vague, ominous and enigmatic phrases to confuse an addressee.

In 'The Lords of Rings', a fantasy novel written by J.R.R. Tolkien, Frodo tells to Gildor, "And it is also said, 'Go no to the Elves for counsel, for they will say both no and yes" (Tolkien, 1954:105). Gildo answers that Elves are cryptic because they think that to give clear tips is dangerous, and it is better for people to figure things out for themselves. It is obvious that Elves tend to use double entendre figure while dealing with people reflected in the tactics of ambiguity. It is done within the frames of the tactics of ambiguity when one of the speakers tries to whitewash the exact answer or truth and apply the strategy of manipulation.

In 'The Matrix Reloaded', a sci-fi action film, directed by T. Wachowskis, one of the secondary characters called Oracle always gives vague prophesies because she just has only a limited access to the future picture. When Neo asks her about the appropriate choice, she answers, "You 've already mane the choice. You are here to understand why you have made it" 
(Washowskis, 2003). In this dialogue the tactics of ambiguity is used to confuse the mind of Neo and to streamline it to another route of thought.

2. 'Cultural Contrast' Dialogue. It is type of a dialogue when one culture is displayed as a splendid sample of advance and amelioration, making a 'stealth' innuendo that other cultures are not so high. At least partly, such dialogue represents a mixture of manipulation and confrontation strategies.

While debating with Emile Mennens, a Belgian anti-corruption official from EU, N. Athanasopoulos, a Greek politician, remarked, "When we Greeks were building Parthenons, you barbarians were still eating acorns" (Nicholas, 2020). In this remark, N. Athanasopoulos hinted that Greek culture is the most ancient and the most respected in Europe. The tactics of insult, emotional appeal and persuasion are applied within the strategy of confrontation here.

Practically in all novels about Harry Potter, there is a cultural opposition between the British wizards and common muggles. It is underlined that wizards are smarter and more advanced.

"Harry Potter: "Don't let muggles get you down."

Ron: "There is no way they'd let me be a Death Eater!" said Ron indignantly.

Harry: My whole family are blood traitors! That is as bad as Muggle-borns to Death Eaters! And they would love to have me," said Harry sarcastically (Rowling, 2010:240).

In this dialogue we can notice the use of the tactics of emotional appeal and persuasion within the strategies of cooperation with magicians and confrontation with muggles.

\section{3. 'Appeal to Family Wisdom' Dialogue.}

It is a type of dialogues, the communicative goal of which is to convince the addressee or the audience using some wise (sometimes humorous) quotation or saying of parents or grandparents of the addresser.

In all societies parents and grandparents are respected. It is not surprising that in literature as well as in journalism many people in their dialogues remember what they were told by their Moms, Dads, Grandmothers and Grandmothers.

In 'Forest Gump', a novel written by W. Groom one of the main characters says: "My momma always said life was like a box of chocolates. You never know what you're gonna get" (Groom,1986:25). In difficult situations he thinks back to his mother`s advice and tries to put it into practice to solve a problem.

In the present-day mass media, this type of dialogue is also widespread, so in his interviews President of the USA, Joe Biden, often remembers his father and his words, especially frequently he quotes the following phrases, "Never complain, never explain" (Colbert, 2020). "My Dad always said, 'Champ, the measure of a man is not how often he is knocked down, but how quickly he gets up" (Colbert, 2020). Through the tactics of integration and persuasion, emotional appeal and informing, J. Biden shapes the strategy of cooperation getting the powerful feedback of his supporters.

4. 'Trial balloon dialogue.' It is a type of dialogue where one of speakers expresses some idea, which could be original, unusual, radical, or even extreme, to test the opinion of the second speaker. The communicative goal of such dialogue is to check the reaction of the addressee or the public opinion of some audience if he or she is a politician.

Being irritated with thorny questions of the press, D. Trump remarked, "Disgusting press writes what it wants" (Ben-Ghiat R., 2020). He did it to check the reaction of mass media and multimedia community on his implied idea to raise state control of independent journalists and editions behaving in a too free way. In this case, D. Trump applies the tactics of affront and control within the strategy of confrontation. 
Joe Biden also was characterized with throwing trial balloons in 2016 and 2017. Being asked about his intention to be nominated for the presidency in 2020 he answered evasively, "I am not closing that door, I have been around too long," he told the 'Today' show in 2017 (Kurz, 2020). In this response, J. Biden applies the tactics of control and ambiguity within the strategies of manipulation and cooperation.

5. 'Blatant Lies' Dialogue. It is a dialogue variant where one of speakers resorts to obvious lie to worm out of a difficult situation.

In 'Gladiator,' a sci-fi novel written in 1926 by P. Wylie, the protagonist named Hugo Danner, being asked by his Army bosses about his supernatural forces, did not tell about the medical experiments of his father, he just answered, "I am from Colorado" (Wylie, 2009:43). Using the tactics of lies within the strategy of manipulation, he deceived his superiors to avoid any problems.

In 'Harry Potter and the Philosopher's Stone,' a fantasy novel written by Rowling J.K., Harry Potter got interested in the images seen by Dumbledore in the Mirror of Erased. The Professor affirmed that he saw "a pair of thick, woolen socks" (Rowling, 1997:115). However, there was Professor's dead sister who got alive once again. Dumbledore said just a part of truth, trying to dodge difficult questions of Harry. So resorting to the strategy of manipulation, Dumbledore applies the tactics of reticence together with the tactics of lies.

6. 'Con Artist (Impostor) Lies' Dialogue. It is a 'type of dialogues when one of speakers employs actor's lie or impersonation trying to deceive his or her addressee.

In 'Beverly Hill's Cop' (1984), an action comedy film made by M. Brest, Axel, the protagonist of the film, played the fool, convincing the prestigious hotel receptionist that he was a journalist: "Don't you think I realize what's going on here, miss? ... I'm not some hotshot from out of town, I'm a small reporter from "Rolling Stone" magazine that's in town to do an exclusive interview with Michael Jackson that's gonna be picked up by every major magazine in the country. I was gonna call the article "Michael Jackson Is Sitting On Top of the World," but now I think I might as well just call it "Michael Jackson Can Sit On Top of the World Just As Long As He Doesn't Sit in the Beverly Palm Hotel 'Cause There's No Niggers Allowed in There!" (Brest, 1984). Axel got what he wanted to get- a top-rated hotel room. His 'Cons Artist Lies' shaped with antithesis (some hotshot-a small reporter), hyperbole (interview ... be picked up by every major magazine in the country), bathos (niggers) and gradation, turned out to be successful. Axel applies the communication tactics of emotional appeal, lies and commiseration though evoking sympathy towards him. These tactics are followed within the frames of the strategy of manipulation.

7. 'Constant-Cheering' Dialogue. It is a type of dialogues when a speaker talks as if he or she always cheers in common conversation. It could testify the appliance of the strategy of entertaining as well as the strategy of manipulation. Though, it could be appropriate or inappropriate.

In 'Whose Line Is It Anyway?', an American comedy TV show, there was such episode: “Greg Proops: Grandpa's dead! Gimme a D! Gimme an E! - Come on! Where 's your enthusiasm? Ryan Stiles: Vasectomy! Vasectomy! Clip clip clip!

Wayne Brady: Okay! Somebody's going to the electric chair! Gonna fry! Gonna fry! Somebody's going to the electric chair! Gonna - Come on! Say What? Come on! Come on!" (Peterson, 2007). In this fragment of discourse, 'Constant Cheering dialogue' looks like a mixture of black humor, rhyme, anaphora, and gloat. It does not look appropriate. The tactics of comism turns out to be floppy.

In 'Fairy Oddparents' (1998-2001), an American animated TV series, created by B. Hartman there is a dialogue between Vicky, a cheerleader and Timmy, an athlete. 
"Vicky. I lie a lot. I cheat in school. I'm scared of cows, love being cruel! I pick my nose when no one looks! I wipe it on my history book!

Timmy: I love cows and doing cheers - ain't blow my nose the past two years!" (Hartman, 2001).

Vicky, using cheering technique and tactics of comism and affront tried to get illusionary superiority over Timmy. However, employing the same tactics, Timmy overplayed Vicky with her own communication weapon.

8. 'Berate and Switch' Dialogue. It is a type of dialogue when an addresser starts scolding an addressee for unfavorable behavior or thoughts and after that suddenly switches to praise and compliment him or her with enthusiasm. Using such types of dialogues, usually a communicant applies the tactics of affront and integration.

In 'The Siege of Macindaw', a fantasy book written by J. Flanagan, a knight conquered a group of Skandian pirates. While seeing the behavior of dirty and greasy beards, beer bellies and rough-tongued pirates, at first, Sir Horace expressed his negative attitude, though, later he added, "They are beautiful" (Flanagan, 2007:45). The usage of antithesis leads to understanding that Sir Horace needs these pirates to fight on his side. It displays the combined application of the tactics of affront, emotional appeal and praise, within the strategies of cooperation and manipulation.

In 'Pacific Rim', an American military sci-fi film directed by G. Del Toro, Marshal Pentecost scolded fighting maneuvers of pilot Becket, calling them break-neck and reckless. However, at the end of his speech he makes a compliment: "In all of my years of fighting $I$ ve never... [smile appears on his face] ... seen anything like that. Well done" (Del Toro, 2013). Using a long antithesis as the base of the 'berate and switch' dialogue, Pentecost mixes the tactics of affront and integration, claiming that though he was against the methods of fight of pilot Becker, they belong to the same team or fighting side.

9. 'Casual Danger' Dialogue. It is a type of a dialogue when in a case of a real danger one of characters starts cracking jokes or giving a sarcastic comment to calm down the others.

In 'Captain America: The Winter Soldier,' an American superhero film directed by A. Russo, Black Widow' tried to convince Captain America to start dating her. She kept cracking dating jokes even during fighting scenes:

"Natasha: [after throwing a man off the roof] How about that secretary who works of the first floor?

Captain America: The one with a lop piercing?

Natasha: Yeah.

Captain America: Yeah...I am not ready for that" (Russo, 2014). In this case, the "casual danger dialogue' is used within the strategies of manipulation and entertaining, applying the tactics of comic ambiguity.

In 'the Jungle Book', written by R. Kipling, one day peasants were turned against Mowgli and came to kill him. Akela, an old wolf, resorts to casual danger dialogue, cracking a joke and at the same time calming down Mowgli.

"The old Tower musket went off with a bang, and a young buffalo bellowed in pain. 'More sorcery!'shouted the villagers. 'He can turn bullets. Buldeo, that was thy buffalo.' 'Now what is this?' said Mowgli, bewildered, as the stones flew thicker. 'They are not unlike the Pack, these brothers of thine, 'said Akela, sitting down composedly. 'It is in my head that, if bullets mean anything, they would cast thee out" (Kipling, 2009:78). In this variant, the "casual danger dialogue' is applied within the strategies of cooperation and entertaining, using the tactics of integration, information and comic mockery. 
10. 'Bread, Eggs, Milk, Squeak' Dialogue. It is a type of a dialogue, when an addresser while speaking about common things, suddenly uses rude words or reveals his or her shockingly negative intentions.

In 'The War Prayer', a short story written by M. Twain, the prayer starts in a traditional and religious way. However, in a while, it calls to "help us to tear their soldiers to bloody shreds" (Twain, 1914). So, the beginning and the end of the prayer is standard, but the middle part is sarcastically twisted. So, in this discourse fragment we see the combination of such communicative strategies as entertainment and confrontation, which are applied through the tactics of affront and comism.

In 'Desperation,' a horror novel written by S. King, a state officer whose soul was caught by a dark creature called Tak, while saying the Miranda rights to a married couple, says, "I am going to kill you" (King, 1996:117). Several minutes later he kills the husband. Trough the 'Bread, Eggs, Milk, Squeak' dialogue he resorts to the tactics of informing and intimidation realizing both of them.

11. 'Derailed Train of Thought' Dialogue. It is a type of dialogues when one character becomes so sidetracked by his or her train of thought that he completely forgets about the original topic.

In 'The Celebrated Jumping Frog of Calaveras County', a short story written by M. Twain, the old narrator tells the story with many sidetracks, forgetting the beginning of the story:

"Well, Smiley kept the beast in a little lattice box, and he used to fetch him down town sometimes and lay for a bet. One day a feller a stranger in the camp, he was come across him with his box, and says: 'What might it be that you've got in the box?'

And Smiley says, sorter indifferent like, 'It might be a parrot, or it might be a canary, may be, but it an't it's only just a frog.'

'Well, thish-yer Smiley had a yeller one-eyed cow that didn't have no tail, only jest a short stump like a bananner..." (Twain, 1867:1). So, applying the tactics of ambiguity and informing, the speaker got lost in his thoughts revealing the tactics of low IQ integration and comism.

In 'Harry Potter and the Chamber of Secrets', a fantasy novel written by J.K. Rowling, Luna Lovegood, a magic reporter, any common conversation finishes with the discussion of the magical equivalents of Loch Ness Monster or Bigfoot (Rowling, 2013). Her 'derailed train of thought 'dialogues testify about the application of the tactics of the obsessive idea and the emotional appeal, which are framed with the strategy of cooperation and manipulation.

12. 'Sliding into Gibberish' Dialogues. It is a kind of dialogues when one of the speakers gradually slides into gibberish.

In 'The Rats in the Walls', a short story written by H.P. Lovercraft, there are examples of ancient gibberish like, "DIV...OPS...MAGNA. MAT," and "P.GETAE ... PROP .. TEMP ... DONA,” and “L. PRAEC...VS... PONTIFI... ATYS” (Lovercraft, 1994:1).

In episode 11 'Golem' of 'Sleepy Hollow' TV series there is such dialogue:

"Lt. Abbie Mills: Chopping down a Christmas tree?

Ichabad Crane: Altogether a nonsensical concept. Celebrating Yuletide with a titular display of Lumber.

Lt. Abbie Mills: Wow. Bah humbug to you too, Ebenezer.

Ichabad Crane: That was gibberish.

Lt. Abbie Mills: Scrooge. A Diskensian character. A grump" (Tobin, 2013).

This dialogue relates to 'Sliding into Gibberish' category. Lieutenant Abbie Mills starts mocking at Ichabad Crane using 'Sliding into Giggerish' dialogue technique 
resorting to the strategies of manipulation and entertaining through the tactics of ambiguity and comism.

Gibberish words and sentences could be employed by children, learning to speak, and senior people because of age illnesses: "Cats, dogs, and babies! It 's Tuesday! Wishes are hopping and trees are west! Food is sitting while the weather is flying" (Yourdictionary, 2021). In this case the speakers are just following the tactics of informing and emotional appeal. However, they are mixed with the tactics of displaying age illness logic or childish age immature logic. From the stylistic point of view, it is a kind of funny logic and absurd.

13. 'Digging Yourself Deeper' Dialogue. It is a type of dialogues, when an addresser starts informing or explaining something more and more, trying to justify himself or herself, though, quite often, he or she gets the opposite result.

In 'Get Smart', an American spy comedy film, directed by L.B. Stern, we can come across the 'digging yourself deeper' dialogue: "Maxwell Smart: I think it's only fair to warn you; this facility is surrounded by a highly trained team of 130 Black Op Snipers. Siegfried: I don't believe you. Maxwell Smart: Would you believe two dozen Delta Force commandos? Siegfried: No. Maxwell Smart: How about Chuok Norris with a BB gun?" (Gartner, 2008). Applying the strategy of manipulation and the tactics of lies, Max persuades his rival to give up because he is surrounded. The tactics of lies is intended to fool up the opponent, supported with Chuok Norris, a precedent name, and anticlimax (a unit from 130 snipers slides into 24 commandos and after that just one Chuok Norris), and comic word BB gun (a gun using BB balls).

In 'Knights of the Dinner Table', a comic book written by Blackburn J. R. there is the following dialogue:

"Chad: Awwwwh, c'mon Patty! When I said girl gamers were lame I wasn't referring to you! You're just like one of the guys.

Patty: Like one of the guys? Your character suddenly hears a rustling in the underbush. Roll for initiative.

Tank: Careful, Chad. You're digging that hole deeper and deeper (Blackburn, 1990).

In this dialogue, Chad uses the tactics of justification and amelioration, though it leads to the negative result. His addressee, Patty, feels offended. So, such dialogue technique leads to the strategy of confrontation through the tactics of affront.

In 'Ravirn', a collection of sci-fi sort stories, written by K. McCullough, one of the main characters often gets into troubles resorting to such type of dialogues.

His companion Melchior mocks at him because of it:

"Judging from past experience and what little I've heard, I'm thinking you're following the pattern where you start out in a lot of trouble, and then through a series of brilliantly chosen words, make it infinitely worse" (McCullough, 2008). The communicative tactics of ridiculing within the strategy of confrontation is based on 'Digging Yourself Deeper' Dialogue technique with clearly shaped antithesis.

14. 'Volleying Insults' Dialogue. It is a type of dialogues when one of the speakers, or even both of them, resort to invective communication in a rude informal register.

In 'Liar Liar', an American comedy film, produced by B. Grazer, there is the following dialogue, "Dana Appleton: Your Honor, I object! Fletcher Reede: You would! Dana Appleton: BASTARD! Fletcher Reede: HAG!' (Grazer, 1997). Such exchange is based on 'Volleying Insults' dialogue, leading to a comic effect. It mixes polite and rude lexicon, displaying bathos (a stylistic figure) and the tactics of affront within the strategy of confrontation.

In 'The Sandlot', an American sports comedy film, produced by M. Burg, there is such dialogue, "Phillips: We play on a real diamond, Porter... Ham Porter: Watch it, jerk. Phillips: 
Shut up, idiot! Ham Porter: Moron!!! Phillips: Scab Eater!!!” (Burg, 1993). In this case 'Volleying Insults' is accompanied with climax and bathos (jerk...idiot! ...moron!!!). The polite and rude lexical units are mixed again actualizing the tactics of affront and the communicative goal of both speakers to get superiority.

In American politics, in spite of the advance of political correctness, there is a long tradition of the political insult.

John Adams, the second president of the USA called Thomas Jefferson, "a mean-spirited, low-lived fellow, the son of a half-breed Indian squaw, sired by a Virginia mullatto father" (Rubino, 2021).

In one of his debates, Donald Trump, the 45th American President, called Hillary Clinton as 'crooked.' In his turn, Berrnie Sanders called Donald Trump as a'pathological liar' (Rubino, 2021).In all these cases we can identify the communicative tactics of mockery, insult and emotional appeal within the communicative strategy of confrontation.

15. 'Insult Backfire' Dialogue. It is a kind of dialogues when an addresser employs the invective lexicon and an addressee resorts to polite communication acts.

In 'Hocus Pocus', an American fantasy horror comedy film, produced by S. Haft, there is the following dialogue, "Billy: Go to hell! Winnie: I have been there, thank you. I find it quite lovely" (Haft, 1993). The first speaker applies the stylistic figure bathos and the tactics of affront, while the second speaker resorts to the tactics of integration and comism. From the stylistic point of view, it looks like irony.

In 'Casino Royale', an American spy comedy film, produced by C. K. Feldman, we can come across the following dialogue: "Lavi: You are crazy. You are actually crazy! Allen: They called Einstein crazy!" (Feldman,1967). In this dialogue 'Insult Backfire' is intensified with climax and oxymoron (Einstein, the brilliant mind, and....crazy). While responding the rude remarks of Lavi, Allen prefers to apply the tactics of comism.

16. 'Contradiction of Arguments' Dialogue. In this type of dialogue, speakers contradict each other. The communicative goal of such dialogue is to neutralize the arguments of the second speaker. People are different, opinions could be completely different too. It could be displayed in emotional fiction and non-fiction dialogues.

In 'How Music Works: The Science and Psychology of Beautiful Sounds, from Beethoven to the Beatles and Beyond' J. Powell presents such dialogue between two famous singers, Anton Schwarz and Luigi Streptococi,

"Hey, Luigi, you are singing every note flat."

"No, Anton, it's you - you are singing sharp. I know because I truly have perfect pitch." "No you are wrong." "No you are wrong." "Flat, flat, flat." "Sharp, sharp, sharp" (Powell, 2011). In this fragment of discourse, two singers utilize the tactics of emotional appeal, persuasion, and affront, within the frames of the strategy of confrontation.

In American mass media the 'Contradiction of Arguments Dialogues' technique is a usual phenomenon. The first debate between Donald Trump and Joe Biden was practically based on it, "Joe Biden: You're the worst President of the USA. Donald Trump: I've done more in 47 months than you in 47 years. Donald Trump: He called the military - stupid bastards. Joe Biden: I have never called them so..." (Trump, Biden, 2020). Almost all argument presented by Joe Biden were bitterly criticized by D. Trump and on the contrary.

In this dialogue the strategy of confrontation is used by both high-rank politicians who resort to the tactics of affront insulting each other, using hyperboles and overstatement. Besides, J. Biden applies the tactics of justification, trying to verify the truth. 
After monitoring and identifying 16 types of dialogues with informal American names, we can classify the communication strategies and tactics within the frames of which these dialogues are employed.

The communicative strategy of manipulation may be achieved through several tactics. It could be applied through the tactics of ambiguity, persuasion, wrong logics, lies and tactics of reticence as well as the tactics of comism.

The communicative strategy of confrontation could be realized basically through the tactics of affront, the tactics of ridiculing (mockery), the tactics of persuasion, and the tactics of wrong or funny logics. It is typically used in American literature and journalism in the form of sarcastic, satiric and black humor remarks and dialogues.

The communicative strategy of cooperation could be reached through the tactics of integration, emotional appeal, comism, control over the situation, persuasion, social approval with adherence to moral standards, and informing.

The communicative strategy of entertaining could be achieved through the tactics of emotional appeal and comism in its four variants: humor, satire, irony and sarcasm.

Table 1

The application of dialogues in $\mathrm{BBC}$ and $\mathrm{CNN}$ feature articles

\begin{tabular}{|l|c|c|}
\hline & CNN & BBC \\
\hline Total number of featured stories (articles) & 26 & 28 \\
\hline Ratio: Dialogues used / No dialogues & $19 / 7$ & $23 / 5$ \\
\hline Dialogues used in percent & $73 \%$ & $82 \%$ \\
\hline $\begin{array}{l}\text { Dialogues with strategies of cooperation (percent from } \\
\text { all dialogues) }\end{array}$ & $9(47 \%)$ & $9(35 \%)$ \\
\hline $\begin{array}{l}\text { Dialogues with strategies of cooperation and } \\
\text { confrontation (percent from all dialogues) }\end{array}$ & $7(36 \%)$ & $9(35 \%)$ \\
\hline $\begin{array}{l}\text { Dialogues with strategies of cooperation and humorous } \\
\text { entertainment (percent from all dialogues) }\end{array}$ & $3(17 \%)$ & $5(30 \%)$ \\
\hline
\end{tabular}

Besides, our scientific research touched upon the issue of the application of dialogues in modern mass media of the USA and Great Britain. We decided to conduct content analysis and to monitor the samples of feature articles (stories) posted by $\mathrm{CNN}$ and BBC during one day. We chose January 19, 2021 (CNN, BBC, 2021). According to our survey from $26 \mathrm{CNN}$ feature stories and $28 \mathrm{BBC}$ feature stories relating to such sections as business, travelling, politics, entertainment and sport, $73 \%$ of CNN feature stories and $82 \%$ of BBC feature stories contained dialogues. The communicative strategy of cooperation is used in $47 \% \mathrm{CNN}$ and $35 \% \mathrm{BBC}$ feature stories with dialogues. The communicative strategy of cooperation and confrontation is employed in $36 \% \mathrm{CNN}$ and $35 \% \mathrm{BBC}$ feature stories, and the communicative strategies of cooperation and humorous entertainment in $17 \% \mathrm{CNN}$ and $30 \% \mathrm{BBC}$ feature stories respectively.

\section{Conclusions}

As a result of the conducted scientific survey based on the monitoring of American multimedia, sixteen types of dialogues with different communicative goals were determined. They are the following: Cryptic Conversation; Cultural Contrast; Appeal to family wisdom; Trial 
balloon dialogue; Blatant Lies; Con artist lies dialogue; Constant cheering; Berate and switch; Casual danger; Bread, Eggs, Milk, Squeak; Derailed Train of Thought; Sliding into Gibberish; Digging Yourself Deeper; Volleying Insults; Insult backfire; Contradiction of Arguments' Dialogue. They are used in fiction and gradually penetrate in non-fiction testifying the blurring the clear-cut line between literature and journalism and the offence of literary journalism trends.

The content analysis of $\mathrm{BBC}$ and $\mathrm{CNN}$ feature stories posted during one broadcasting day showed that the majority of them ( $73 \%$ of CNN feature stories and $82 \%$ of BBC) use dialogues. The main communicating strategies applied in them are the communication strategies of cooperation, confrontation and entertainment (humorous).

Monitoring, identifying and classifying the modern types of dialogues, used by English-speaking authors and journalists in their fiction and non-fiction works, belong to the promising area of the scientific survey of those who specialize in literary criticism, philology and journalism.

We think that this article will inspire Ukrainian scholars and practitioners to meet the new literary journalism challenges and to come up with breakthrough ideas relating to it. Advanced knowledge of this material would lead Ukrainian students and journalist to better shaping of English multimedia content.

\section{References}

Ben-Ghiat R. CNN. Trump 's 'trial balloons' test our commitment to freedom. (November 8, 2020). URL at: https://edition.cnn.com/2017/11/08/opinions/trump-authoritarian-trial-balloons-ben-ghiat/index.html (Retrieved 09.11.2020).

Blackburn J.R. (1990). Knights of the Dinner Table. Comic book. URL: www.kenzerco.com (Retrieved 03.01.2021).

Brest M. (1984). Beverly Hills Cop. Action-comedy film. Paramount Pictures. URL: https:// www.youtube.com/watch? $v=$ RzQDtZeJvLI (Retrieved 10.11.2020).

Burg M. (1993). The Sandlot. Sports comedy film, URL: http://www.imdb.com/title/tt0108037/ trivia? tab=qt\&ref_=tt_trv_qu (Retrieved 03.01.2021)

Colbert S., Biden J., Vice President Joe Biden Interview, Part 1(2020). The Late show with Stephen Colbert. URL: https://www.youtube.com/watch? $v=o p V a E C \_W x W s \& t=2 s$ (Retrieved 21.09.2020).

Del Toro G. (2013) Pacific Rim. American military sci-fi film. Warner Brothers Pictures.URL: https://www.warnerbros.com/movies/pacific-rim (Retrieved 03.01.2021)

Feldman C. (1967). Casino Royale Spy comedy film. URL: http://www.imdb.com/title/tt0061452/ trivia? tab $=q t \& r e f=t t$ trv_qu (Retrieved 03.01.2021)

Flanagan J. (2007) The Siege of Macindaw. Fantasy. Adventure. Australia, Random House, $371 \mathrm{p}$.

Gartner A.(2008). Get Smart. Spy comedy film. Warner Bros. URL: http://www.imdb.com/title/ tt0425061/(Retrieved 03.01.2021).

Grazer B. (1997). Liar Liar. Comedy film. URL: http://www.imdb.com/title/tt0119528/triv$i a ? t a b=q t \& r e f=t t$ trv_qu (Retrieved 03.01.2021)

Groom W. (1986). Forest Gump. Novel. USA: Doubleday. 228 p.

Haft S. (1993). Hocus Pocus. Fantasy horror comedy film. URL: http://www.imdb.com/title/ tt0107120/trivia?tab=qt\&ref_=tt_trv_qu (Retrieved 03.01.2021)

Hartman H. (1998-2001). Fairy Oddparents. American animated TV series. Nickelodeon. URL: https://www.nick.com.pl/ (Retried 03.01.2021). 
Hornmoen H., Steensen S. (2014). Dialogue as a Journalistic Ideal. Journalism studies. (April 16, 2014), available at: http://www.tandfonline.com/doi/full/10.80 (accessed 21.04.2020). King S. (1996). Desperation. Horror novel. USA, Viking, 704 p.

Kipling R. (2009) The Jungle Book. Collection of stories. Penguin Random House Children's $U K, 256 \mathrm{pp}$.

Kurz H., Fox news. Biden 2020 trial balloon: Why some liberals say his past haunt him (November 17,2017 ). URL: https://www.foxnews.com/politics/bidens-2020-trial-balloon-why-someliberals-say-his-past-would-haunt-him (Retrieved 09.11.2020).

Levy D.M. (1979):Communicative goals and strategies: between Discourse and Syntax. Article. N.Y. Academic Press, 1979 Vol. 12. P. 183-210.

Lovercraft H.P. (1994). The Rats in the Walls. Short story. URL:

https://www.hplovecraft.com/writings/texts/fiction/rw.aspx (Retrieved 03.06.2021).

McCullough K. (2008). Ravirn. Codespell. Sci-fi story. URL: https://kellymccullough.com/thewebmage-story/codespell/ (Retrieved 03.01.2021).

Nicholas N. Do modern Greeks feel continuity with their ancient civilization like Indians or Chinese? Opinion article. URL: https://www.quora.com/Do-modern-day-Greeks-feel-continuity-with-their-ancient-civilization-like-Indians-or-Chinese (Retrieved 03.01.2021).

Peterson D. (1998-2007) Whose Line Is It Anyway? Episode 'Scenes from a Hat. 'American comedy TV show. ABC. URL: https://www.youtube.com/watch? $=$ po55FFy08as\&lc=UghohxXm HoF9XgCoAEC (Retrieved: 03.01.2021)

Powel J. How Music Works: The Science and Psychology of Beautiful Sounds, from Beethoven to the Beatles and Beyond. (2011). Non-fiction. USA: Little, Brown and Company, 2011, 272 pages.

Rowling J.K. Harry Potter and the Prisoner of Azkaban. (2010). Fantasy novel. UK: Bloomsbury, $317 \mathrm{pp}$.

Rowling J.K. (2013). Harry Potter and the Chamber of Secrets. Fantasy Novel. UK: Bloomsbury. 384 pp.

Rowling J.K. (1997) Harry Potter and the Pholosopher's Stone /fantasy novel/ UK:Bloomsburry. $-1997-223 \mathrm{pp}$.

Rubino R. Political Insults In American Politics Are As Old As the Republic. Opinion article. URL: https://www.huffpost.com/entry/political-insults-in-american-politics- are-as-old-as_b_59dc22c9e4b0a1bb90b8308e (Retrieved 03.01.2021).

Russo A., Russo J. (2014). Captain America: The Winter Soldier. Superhero film. Marvel Studios. URL: https://hhdmovies.org/captain-america-the-winter-soldier-2014-Watch-online-on123movies/ (Retrieved 03.01.2021).

Thai P. (2017). The definition of a dialogue, its types and ways of writing. (May 17, 2017), available at: https://www.javascriptbank.com/definition-of-a-dialogue-its-types--ways-ofwriting.html (accessed 21.04.2020).

Tobin J.M. (2013). The Golem. Sleepy Hollow. Action, Crime, TV series. Fox. URL: https:// www.imdb.com/title/tt3335202/ (Retrieved 03.01.2021)

Tolkien J.R.R. (1954). The Lord of Rings. Fantasy novel. UK, Allen \& Unwin, 1216 p.

Trump D., Biden J., First 2020 Presidential Debate between Donald Trump and Joe Biden (30.09.2020) URL: https://www.youtube.com/watch? $v=w W 1 l Y 5 j F N c Q$ (Retrieved 30.09.2020). Twain M. (1914). The War Prayer. The New York Times, December 7, 1914 URL: http:// www.twainquotes.com/19141207.html (Retrieved 30.05.2021).

Twain M. (1867). The Celebrated Jumping Frog of Calaveras County. Short story. URL: https:// twain.lib.virginia.edu/projects/price/frog.htm (Retrieved 03.05.2021). 
Washowskis T. (2003). The Matrix Reloaded. Science fiction action film. URL: https:// www.digit.in/digit-binge/movies/the-matrix-reloaded-6455.html (03.01.2003).

Wolfe, T., \& Johnson, E. W. (Eds.). (1975). The New Journalism. London, UK: Picador, 1975, 394 pages.

Wylie P., (2009). Gladiator. Alfred A. Knopf. 332 p.

Yourdictionary.com. (2021). Gibberish. URL: https://examples.yourdictionary.com/examples-of-gibberish.html (Retrieved 03.01.2021).

\section{References for tablets 1 and 2}

CNN Featured Sections News URL: https://edition.cnn.com (Retrieved 19.01.2021)

BBC News. Features \& Analysis. URL: https://www.bbc.com/news/world-europe-55716338 (Retrieved 19.01.2021) 